\title{
A case of renal cell carcinoma and angiomyolipoma in an adolescent girl
}

\author{
J W Rood, ${ }^{1}$ MB ChB, Dip HIV Man; K P Mokhobo, ${ }^{2}$ MB ChB, DPH, DTM\&H, FCPSA, Dip Cardiol (Copenhagen) \\ ${ }^{1}$ Department of Internal Medicine, Tygerberg Hospital, Cape Town, South Africa \\ ${ }^{2}$ Department of Internal Medicine, Potchefstroom Provincial Hospital, North West Province, South Africa
}

Corresponding author: J W Rood (jacquesrood@gmail.com)

We describe a case of renal cell carcinoma in the right kidney together with an angiomyolipoma in the left kidney, encountered in an adolescent girl at Potchefstroom Provincial Hospital, North West Province, South Africa.

S Afr Med J 2016;106(8):795-796. DOI:10.7196/SAMJ.2016.v106i8.10519

Renal cell carcinoma is the most common cancer involving the kidneys. It is reported to occur in $3 \%$ of all malignancies in adults and accounts for $90-95 \%$ of all cancers involving the kidneys. The peak age of diagnosis is between 50 and 70 years; in recent years the median age has been given as 64 . There is also a slight predominance in males, with a ratio of $2: 1 .^{[1]}$ Renal cell carcinoma has been attributed primarily to smoking, but other risk factors include conditions such as acquired cystic diseases of the kidneys, tuberous sclerosis and von Hippel Lindau (VHL) syndrome. Approximately 35\% of patients with VHL disease develop clear renal cell carcinoma. ${ }^{[1]}$

Only $10 \%$ of patients present with the classic triad of flank pain, haematuria and a flank mass. The 5-year survival rate for stage 4 renal cell carcinoma is between $0 \%$ and $20 \% \cdot{ }^{[1]}$

We present a rare case of dual pathologies, renal cell carcinoma in the right kidney and angiomyolipoma in the left, which is still more unusual because the patient was a 17-year-old girl. Verbal consent for the study and publication of material was obtained on initial presentation from the patient as well as the parent.

\section{Case report}

A 17-year-old girl of mixed race was referred to Potchefstroom Provincial Hospital, North West Province, South Africa, from the local clinic with what was thought to be splenomegaly. On arrival at the secondary hospital, the abdominal mass was confirmed and was reported probably to be of splenic origin. The history confirmed that the mass had been present for 5 months but had not caused problems until now. She had left-sided flank pain and dysuria, with no frank haematuria. Urine dipsticks showed microscopic haematuria (blood $4+$, protein $1+)$. She also complained of arthralgia, especially in the lower region of the back. There was intermittent nausea but rarely vomiting. She had developed a rash/freckles (pale reddish-brown soft small papules) on the face 8 months prior to initial presentation and was referred from the clinic with a query of angiofibroma (Fig. 1). Subsequent work-up for systemic lupus erythematosus was reported to be negative. The rash was reviewed and labelled as papulosa nigra, a normal variant of pigmented skin without any pathological features. No biopsy was done. The patient had no vaginal bleeding or discharge and reported normal bowel function; urine output was normal. She was not coughing and had no complaints of any neurological or cardiovascular symptoms, and reported no smoking or alcohol use. She reported not being sexually active, and a pregnancy test confirmed that she was not pregnant. Menstruation was reported as normal. She had no travel history, medical comorbidities or allergies. She was not using any form of contraception. There was a family history of malignancy in her brother, but the family did not know what type it was. She had no history of tuberculosis and had tested negative for HIV in the weeks preceding presentation.

\section{Physical findings}

The physical findings were unremarkable considering the underlying pathology. The patient was slightly underweight with a body mass index of $19 \mathrm{~kg} / \mathrm{m}^{2}$. She was not pale or oedematous and no rash was seen. The findings on cardiovascular, respiratory and neurological examination were essentially normal apart from a slightly elevated blood

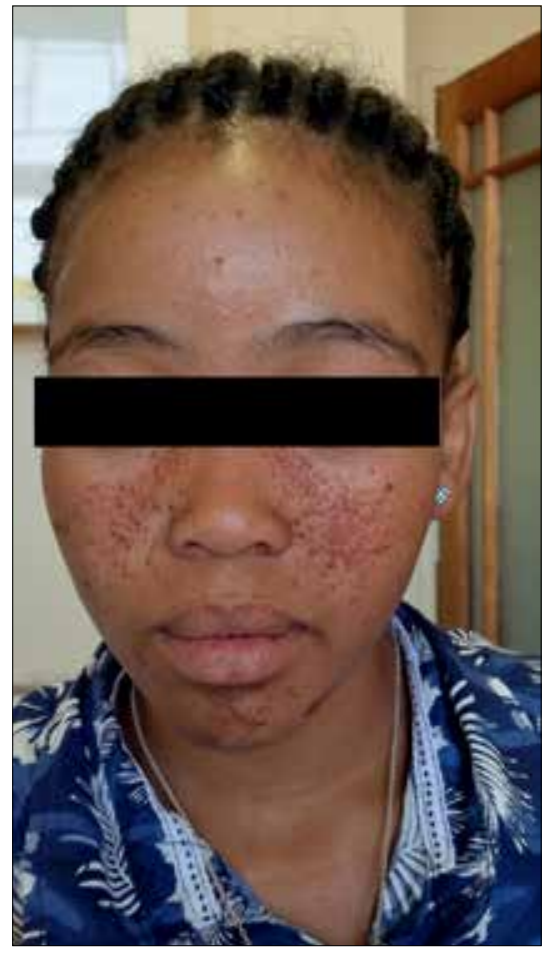

Fig. 1. Possible angiofibromas indicative of tuberous sclerosis.

pressure of 145/89 $\mathrm{mmHg}$ and a persistent mild tachycardia of $106 \mathrm{bpm}$. She had a slight fever of $37.8^{\circ} \mathrm{C}$ and maintained saturation of $98 \%$ on room air. Abdominal examination revealed an abdominal mass on the left side measuring $\sim 10 \mathrm{~cm}$ below the costal margin that moved inferiorly on inspiration. A notch was felt which at that time led the examiner to believe it was a massive spleen. The abdomen was soft and only mildly tender over the mass with no guarding or rebound tenderness. Bowel sounds were present and the liver was not palpable. 
Side-room investigations showed microscopic haematuria (4+) and proteinuria $(1+)$. The haemoglobin concentration was $11.5 \mathrm{~g} /$ $\mathrm{dL}$ and a pregnancy test was negative. Blood samples were taken for splenomegaly work-up at the time and revealed nothing further to indicate the origin of the mass. Kidney function (urea $2.4 \mathrm{mmol} / \mathrm{L}$, creatinine $51 \mu \mathrm{mol} / \mathrm{L}$, estimated glomerular filtration rate $>60 \mathrm{~mL} / \mathrm{min} / 1.73 \mathrm{~m}^{2}$ and electrolyte levels were normal, as was liver function (alkaline phosphatase $96 \mathrm{U} / \mathrm{L}$, gamma-glutamyl transpeptidase $16 \mathrm{U} / \mathrm{L}$, alanine aminotransferase $10 \mathrm{U} / \mathrm{L}$, aspartate aminotransferase $18 \mathrm{U} / \mathrm{L}$, total bilirubin $4 \mu \mathrm{mol} / \mathrm{L}$, albumin $42 \mathrm{~g} / \mathrm{L}$, total protein $85 \mathrm{~g} / \mathrm{L}$ ). A full blood count (white cell count $6.31 \times$ $10^{9} / \mathrm{L}$, haemoglobin $11.6 \mathrm{~g} / \mathrm{dL}$, platelets $264 \times 10^{9} / \mathrm{L}$ ) was normal. A malaria screen, enzyme-linked immunosorbent assay for HIV and antinuclear antibody were negative. The C-reactive protein level was $32 \mathrm{mg} / \mathrm{L}$. The erythrocyte sedimentation rate (ESR) was raised at $105 \mathrm{~mm} / \mathrm{h}$. The high ESR together with the presence of the mass alerted the clinician to serious pathology. The patient was sent for an urgent ultrasound scan, which revealed kidneys of normal size but with increased echogenicity. No hydronephrosis was observed, but a hypoechoic mass of $5 \times 5 \mathrm{~cm}$ in the midpole of the right kidney and a tiny cyst on the lower pole of the left kidney were seen. The bladder, liver, gallbladder, spleen, pancreas and uterus were reported to be normal. The ovaries were not visualised owing to gas dilating the bowel. The patient was sent for an urgent computed tomography (CT) scan of the abdomen with contrast. The following day, the clinician was called to assess the CT scan together with the radiologist. The radiologist reported a hypodense mass with hyperdense vessels inside the lower part of the left kidney; it also consisted of fatty density and appeared hypervascularised after administration of contrast medium. On first glance, the mass measured $63 \times 126 \mathrm{~mm}$ but on review it was $150 \times 90 \mathrm{~mm}$ (Fig. 2). This mass was compressing the collecting system of the upper part of the left kidney as well as the aorta and some small bowel loops. Another enhancing solid mass was present in the middle part of the right kidney, measuring $51 \times$ $58 \mathrm{~mm}$ in diameter (Fig. 3). Neither ureter was dilated and there was good excretion of the contrast medium by both kidneys. No enlarged retroperitoneal lymph nodes were seen. There were some small sclerotic lesions in the thoracic and lumbosacral vertebral bodies and both iliac bones, suggestive of bone metastases.

The patient was referred to a tertiary setting for a nephrologist to perform a confirmative biopsy of the renal masses and provide further management.

\section{Discussion}

A search of the literature revealed articles describing these dual pathologies in one individual. ${ }^{[2-4]}$ One of them had a unifying diagnosis of tuberous sclerosis. ${ }^{[3]}$ These articles suggest that one should look for renal involvement in patients with tuberous sclerosis complex (TSC). ${ }^{[2-4]}$ Could this patient have TSC, or could the angiomyolipoma be unusual renal metastases presenting radiologically as angiomyolipoma ${ }^{[5]}$ Could her freckles be mistaken for angiofibromas, which would support the diagnosis of tuberous sclerosis? These are important considerations in this case that may offer some treatment options. For example, she could receive treatment with everolimus (Afinitor), which is used for TSC and has been proven to have a $42 \%$ response rate in double-blind, placebocontrolled phase III trial studies. ${ }^{[6,7]}$

\section{Conclusion}

This is an uncommon case of dual renal malignancies in a young girl, with a suspicion of TSC as the underlying cause.

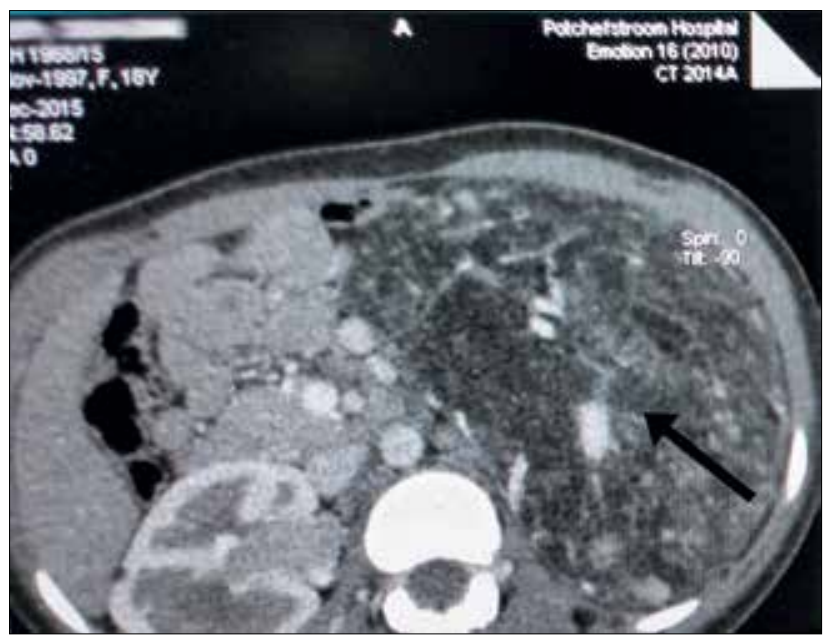

Fig. 2. Angiomyolipoma in the left kidney (arrow).

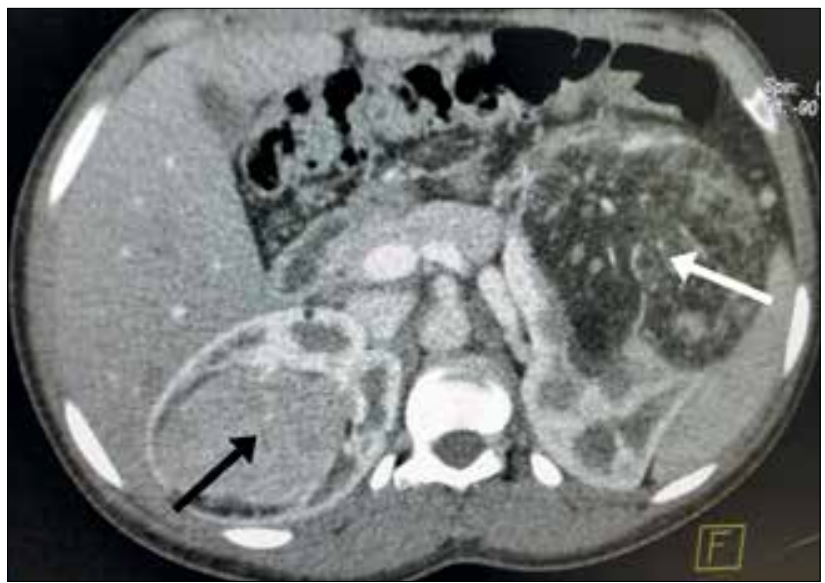

Fig. 3. Right kidney showing clear solid mass (black arrow) and left kidney deformed due to angiomyolipoma (white arrow).

The patient was referred to a tertiary setting for biopsy and further management. In the referral letter it was suggested that a diagnosis of TSC be considered.

Acknowledgement. Dr M J Kleynhans and Dr M Radebe are acknowledged for their critical evaluation of the manuscript.

1. Scher HI, Rosenberg JE, Motzer RJ. Bladder and renal cell carcinoma. In: Longo DL, Fauci AS, Kasper DL, Hauser SL, Jameson J, Loscalzo J, eds. Harrison’s Principles of Internal Medicine. 19th ed. New York: McGraw-Hill, 2015

2. Korula S, Ekbote A, Kumar N, Danda S, Agarwal I, Chaturvedi S. Renal manifestation of tuberous sclerosis among children: An Indian experience and review of literature. Clin Kidney J 2014;7(2):134137. DOI: $10.1093 / \mathrm{ckj} / \mathrm{stt} 162$

3. Kakkar A, Vallonthaiel AG, Sharma MC, Bora G, Panda A, Seth A. Composite renal cell carcinoma and angiomyolipoma in a patient with tuberous sclerosis: A diagnostic dilemma. Can Urol Assoc J and angiomyolipoma in a patient with tuberous

4. Mei M, Rosen LE, Reddy V, Cimbaluk DJ, Gattuso P. Concurrent angiomyolipomas and renal cell neoplasms in patients without tuberous sclerosis: A retrospective study. Int J Surg Pathol 2015;23(4):265-270. DOI:10.1177/1066896915569914

5. Sung CK, Kim SY, Woo S, et al. Angiomyolipoma with minimal fat: Differentiation of morphological and enhancement features from renal cell carcinoma at CT imaging. Acta Radiol 2015; Dec 11 [Epub ahead of print]. DOI:10.1177/0284185115618547

6. Bissler JJ, Kingswood JC, Radzikowska E, et al. Everolimus for angiomyolipoma associated with tuberous sclerosis complex or sporadic lymphangioleiomyomatosis (EXIST-2): A multicentre, randomised, double-blind, placebo-controlled trial. Lancet 2013;381(9869):817-824. DOI:10.1016/ S0140-6736(12)61767-X 7. Everolimus reduces kidney tumors in tuberous sclerosis complex. Medscape Medical News, 11 Jan
2013.

Accepted 14 January 2016. 